\title{
Las formas del trabajo femenino y su representación en el romance La noble porquera
}

\author{
The Nature of Women's Work \\ and its Representation in the Spanish \\ Folk Ballad La noble porquera
}

\author{
Ignacio Ceballos Viro \\ Universidad Internacional de La Rioja
}

\section{RESUMEN}

En este estudio se analiza la interpretación que el romance tradicional La noble porquera / La porquerola ofrece acerca del trabajo femenino. Partiendo de un análisis del relato desde la perspectiva antropológica, se examinan en primer lugar las causas y consecuencias del conflicto entre suegra y nuera, el cual funciona como motor de la trama y viene a desembocar en la imposición de unas determinadas cargas laborales sobre la nuera. Lo interesante a continuación es dar razón de por qué el romance considera esos trabajos en particular como un castigo. Para ello, se determina el valor que pudieran tener algunas circunstancias socioculturales en la transmisión del romance, como el hecho de que muchas informantes se dedicaran precisamente a las tareas de cuidado del ganado. Finalmente, se presentan unas conclusiones sobre el grado de incidencia del medio socioeconómico en los relatos orales y sobre las características de la propia perspectiva de análisis antropológico de la literatura.

Palabras clave: Romancero, Familia, Nuera, Suegra, Trabajo, Castigo

\section{SUMMARY}

This article deals with the depiction of women's work found in the traditional ballad La noble porquera / La porquerola. Firstly, the story is analyzed from an anthropological perspective. Then, the causes and consequences derived from the conflict between mother-in-law and daughterin-law have been examined. This clash is actually the trigger of the plot, which results in the burden of work thrown upon the young wife. The next aim of this study is to determine why those particular duties are seen as a punishment in the ballad. In order to do this, we consider the sociocultural circumstances in which the ballad was passed on; for instance, the fact that many ballad informants worked doing the same tasks that were criticized in the story (like breeding the cattle). Finally, we set out some conclusions about the impact of the socioeconomic background on the oral tradition and the nature and scope of the anthropological analysis in literature.

Key words: Folk Ballad, Family, Daughter-in-law, Mother-in-law, Work, Punishment 
Cualquier acercamiento al romancero, el principal exponente de la poesía narrativa de tradición oral hispánica, suscita una serie de preguntas sobre su propia existencia, su utilidad y su sentido. Algunas de ellas podrían ser: ¿por qué en determinadas regiones se cantan y recitan unos romances, y en otras no? ¿Qué significados y valores transmite la literatura oral a los miembros de las sociedades que la conservan? ¿Hasta qué punto está relacionado el mundo simbólico y ficcional del romance con la realidad extradiegética a la que pertenecen los cantores? Las páginas siguientes surgen de un intento por hacer más inteligible ese asombro que causa la propia existencia del romancero tradicional, y tratan de atar algún cabo a la resolución de dichos interrogantes, analizando la cuestión del trabajo femenino en un romance concreto.

La noble porquera, llamada en ocasiones La gentil porquera o La dama pastora (no ha de confundirse con La bella pastora catalana), es un romance bastante conocido en algunas regiones del mundo hispánico. Desde mediados del siglo XIX, se ha venido recolectando un corpus de unas 140 versiones diferentes, halladas en las provincias de Asturias, Cantabria, Palencia, Burgos, Salamanca, La Rioja, Huesca, Lérida, Gerona, Barcelona, Tarragona, Alicante, Islas Baleares, así como entre los sefardíes del norte de Marruecos y de Sarajevo. Si ampliamos nuestro encuadre, se constata además que La noble porquera (La porqueirola / porquerola en sus más numerosas versiones catalanas) es la rama hispánica de una balada de amplísima difusión. El tema es originario presuntamente de Francia, donde se conoce con el nombre de $L a$ porcheronne, y desde allí se generaron descendientes en muchas de las lenguas de Europa (Stein 1979; Ceballos 2010: 423-477).

El argumento de La noble porquera es bastante sencillo en líneas generales, si prescindimos de las innumerables variantes que suelen caracterizar la vida del romancero oral. Resumámoslo incluyendo algunos rasgos de análisis antropológico: en una situación doméstica de virilocalidad (corresidencialidad del joven matrimonio protagonista con la familia del marido), acaece la ausencia prolongada del esposo; la suegra, entonces, a pesar de las advertencias de su hijo, maltrata a la nuera obligándola a vivir como una criada y a realizar las duras tareas de cuidado del ganado; cuando el marido regresa, finalmente, averigua todo lo que ha ocurrido en su ausencia y restablece el orden. En un apéndice presento tres versiones del romance, pertenecientes a localidades distantes, con el fin de que testimonien los pormenores del relato; animo a leerlas antes de proseguir, si no se está muy familiarizado con el romance en cuestión ${ }^{1}$.

\section{LAS CAUSAS DEL CONFLICTO ENTRE LA SUEGRA Y LA NUERA EN EL RELATO}

El conflicto que subyace en este romance es uno relativamente habitual en la baladística europea y otros tipos de literatura oral: la rivalidad entre suegras y nueras. Y esta problemática se concreta aquí en la conjunción de dos factores: la exogamia más la residencia virilocal. Es este tipo de pauta de residencia, en el que la mujer

\footnotetext{
${ }^{1}$ Se podrá encontrar un inventario (casi) completo de las versiones de La noble porquera en Ceballos (2010: 148-159). En el mismo trabajo (535-559) se editan varios de los textos.
} 
debe abandonar el hogar natal para marcharse a vivir con la familia de su marido, el que es germen de las ulteriores tensiones entre suegras y nueras. El choque surgido al coincidir ambas en el mismo grupo doméstico no se produce en condiciones de igualdad: la nuera posee un estatus de extraña, desprotegida, conviviendo con personas a las que no la ligaba anteriormente ningún vínculo, y además alejada de su propia familia de orientación (siguiendo la terminología de Murdock 1965: 13) y de la ayuda que ésta podría prestarle en casos de necesidad. Martine Segalen resume diáfanamente las expectativas para la esposa en este tipo de comunidades (Segalen 1992: 179) $)^{2}$ :

Además, la regla de la residencia patrilocal (la joven casada va a vivir a casa de los padres de su esposo) hace de ella una extranjera en su morada. Sometida a su suegra, tendrá que esperar a serlo a su vez para poder decir su propia palabra.

La relación con la familia de orientación y con el resto de parientes de la localidad natal tras el matrimonio debía de ser normalmente escasa en las sociedades tradicionales, como la medievalizante que plantea nuestro texto, con los medios de transporte característicos de la era preindustrial. En este sentido, la situación de la nuera-porquera parece agravarse debido precisamente al alejamiento geográfico sucedido tras su matrimonio, puesto que no se menciona en el relato a ninguno de sus parientes, ni se contempla como posibilidad la recepción de su ayuda. Y este alejamiento deviene (a falta de otra explicación explícita en el poema) de la propia exogamia, motivo por el cual la hemos mencionado hace unas líneas como uno de los factores antropológicos relevantes en el análisis de nuestro romance; en palabras de Ralph Linton (Linton 1993 [1936]: 59):

El hecho de que una mujer viva con la familia de su esposo es menos importante, en la práctica, que el grado de aislamiento de su propia familia que ello representa. Si continúa viviendo en el mismo pueblo con sus propios hermanos y hermanas, la unidad consanguínea no se habrá desmembrado seriamente. [...] Al primer indicio de dificultades podrá buscar apoyo entre sus propios parientes masculinos, quienes probablemente no tienen ninguna simpatía por la familia de su esposo.

Planteada de este modo la situación doméstica en la secuencia inicial de La noble porquera, la animadversión de la suegra hacia la nuera aflora cuando el marido se ausenta, generalmente, se dice, porque debe ir a la guerra. El esposo había enco-

\footnotetext{
${ }^{2}$ En otra página de su libro, Segalen (1992: 40) expone el caso de la zadruga yugoslava (una comunidad rural formada por un grupo doméstico extenso, con los bienes en común), en el que estas características de rivalidad entre mujeres podría ser paradigmático y muy aplicable a nuestro romance: "como el matrimonio era exógamo (es decir, entre las diferentes zadrugas) [...], las nueras eran extranjeras y rivales, envidiando a las hijas de la casa que eran dispensadas de los trabajos domésticos y se dedicaban a su ajuar». En el ámbito hispánico, también es fácil dar con descripciones semejantes, referidas a aquellas regiones del norte peninsular en las que existe patrilocalidad: "La esposa/nuera entra en la casa como parte de una transacción económica. Le corresponde trabajar en los campos y en la casa, cuidar de los niños y atender a los suegros; más tarde, cuando éstos desaparezcan, será la señora o dona de la casa, pero mientras tanto el día le carga de obligaciones sin correspondientes derechos. Hasta para mimar a sus hijos necesita de dinero que no está en sus manos. Su posición estructural, de carácter de intrusa en nido ajeno, facilita depresiones nada infrecuentes en ella" (Lisón 1980: 104-105).
} 
mendado a su madre el cuidado de su mujer, y le ruega, antes de partir, que le profese un trato equivalente al de sus propias hijas. Es esta última la expresión ingenua del deseo de armonía entre suegra y nuera que, como hemos anticipado, está muy lejos de cumplirse: la suegra degrada a la nuera al nivel de una criada y la envía fuera del hogar a cuidar del ganado, día tras día durante años.

\section{LA INTERPRETACIÓN DEL TRABAJO FEMENINO COMO CASTIGO}

No hay duda de que el romance presenta el trabajo femenino en el campo como una tarea degradante dentro del reparto de roles del grupo doméstico. En las versiones catalanas el marido insiste en cuáles deben ser las únicas tareas físicas que ella realice en su ausencia:

-Ay, mare, la meva mare, aquí-os deixo ma mullé,
que no li feu fé feynetas, qu' ella no las pugui fé:
las feynetas qu' ella 'n feya son brodé, cusé y mitxé.
Si 'l brodé no li agrada ya ni fareu fé cusé;
si 'l cusé no li agrada ya ni fareu fé mitxé;
si 'l mitxé no li agrada ya no ni fareu fé re ${ }^{3}$.

Sin embargo, este mensaje está en clara discordancia con los usos y costumbres de las capas populares de la población, precisamente aquellas que han conservado el romance como parte de su tradición literaria. Dependiendo de la región geográfica donde se haya recogido, las esposas realizaban unos trabajos u otros, y con frecuencia también los de bordar y coser; pero en cualquier caso la exclusividad del labrado de prendas era muy excepcional ${ }^{4}$. Probablemente este fragmento del discurso del romance está en conexión con la clase social a la que se supone que pertenecen los protagonistas. Constatamos que muchas versiones hablan de la nobleza de la esposa ("Casi's amb donya Maria, que és filla d'un cavaller"s), y al esposo, también caballero, se le nombra siempre con el "don" delante (don Bueso, don Güeso, don Jaume, don Joan del Vilatge o don Guillem); a la hora de describir la situación económica de la casa en que viven, es fácil ver que el romance mantiene la coherencia con esta posición social acomodada:

\footnotetext{
${ }^{3}$ Versos 7-12 de una versión de Barcelona, de la región del Penedès, recogida por Manuel Milà i Fontanals (Milà 1882: 200-202).

${ }^{4}$ De hecho, este trabajo femenino generaba una competitividad entre las mujeres de la casa, agudizada en las regiones donde existe el sistema de heredero único (zonas del norte de España) por la envidia de las cuñadas hacia la nuera: "La novia al casar con el heredero no sólo adquiere una posición superior a sus cuñadas y cuñados que moran bajo el mismo techo; además de ser de for y ajena, desbanca y desplaza a los de dentro. Por eso trae un regalo para cada uno de ellos, además de la dote para la casa, que será suya. Desde luego que para ella tiene que trabajar diariamente, con dureza, para hacerse digna de su posición. Ninguno de sus afines en la casa le perdonaría su desidia, falta de interés o rigor en el cumplimiento de sus deberes" (Lisón 1974: 85-86).

${ }^{5}$ Verso 2 de una versión de Ulldemolins (Tarragona), de Josepa Franquet i Llurba, recogida en 1932 por Xavier Gols y Antoni Brunet, publicada en Massot (1996-2007: XV, 293-294).
} 
Eso sí, señor, sí, señor melitar, en casa de mi suegra la solían dar [posada], en una casa grande, 'n el medio del lugar. // A la casa de ma sogra solen fer la vida bé. ${ }^{6}$

Esta "nobleza" de la nuera, que configura el mismo título del romance y sobre la que luego volveré, amplifica la gravedad del castigo que ejecuta la suegra, ya de por sí grave, pues no se limita a la dureza del trabajo pastoril sino que se exacerba al combinarse con el desprecio en el hogar y la negación de la mesa y el lecho para dormir.

Esto explica la visión que se ofrece del trabajo femenino en la ficción romancística. En el mundo extradiegético, la mujer siempre ha participado en las tareas productoras del grupo doméstico, entendido éste como unidad económica. El reparto de roles en la familia consiste en una división sexual del trabajo, tal y como se afirma desde la antropología 7 y ello nos lleva a considerar más que nunca la familia al completo como una unidad de producción ${ }^{8}$. Como parte de ella, el trabajo femenino se ha venido desarrollando de tres maneras: en forma de trabajo asalariado en el exterior de la casa, en forma de trabajo doméstico interior a la casa, o en forma de faenas agropecuarias vinculadas a la casa. Procuraré exponer brevemente en qué consiste cada una con el fin de contextualizar mejor los significados implícitos del motivo del "trabajo como castigo" en La noble porquera.

Empezando por lo primero, el que las esposas aporten un salario a la economía familiar no es un invento reciente. En palabras de Mary Nash, es un error de perspectiva histórica creer que la industrialización fue el momento en que las mujeres accedieron al trabajo (Nash 1993: 585):

Las mujeres siempre han trabajado, su experiencia laboral ha sido compleja y ha representado una aportación decisiva a la supervivencia económica de las familias trabajadoras. Hasta hace poco, la percepción historiográfica tradicional de la trayectoria de las trabajadoras había ignorado la globalidad de su experiencia laboral en cuanto a combinación de trabajo remunerado y trabajo doméstico. [...] Los trabajos ya clásicos de Louise Tilly y Joan Scott [...] han cuestionado la interpretación de la industrialización como momento de ruptura en lo que fue la experiencia laboral femenina y han subrayado los factores de continuidad en esta experiencia en el mundo industrial que derivan de la práctica laboral habitual de las mujeres en las sociedades preindustriales.

${ }^{6}$ Versos 51-53 de una versión de Uznayo (Polaciones, Cantabria), de Juliana García, recogida por Diego Catalán y otros en 1977 y publicada en Petersen (1980: I, 91-94). Y verso 19 de la versión de Ulldemolins (Tarragona) ya citada.

${ }^{7}$ Cf. Claude Lévi-Strauss: "Cuando se afirma que un sexo debe desempeñar ciertas tareas, esto significa también que están prohibidas para el otro. Ante eso, la división sexual del trabajo no es otra cosa que una invención para instituir un estado de dependencia recíproco entre los sexos" (Lévi-Strauss 1995 [1956]: 309). Desde la perspectiva de la antropología materialista, se suele considerar que la división sexual del trabajo viene impuesta por causas fisiobiológicas, aspecto con el que Lévi-Strauss no está de acuerdo (cf. Bonte e Izard 1996: 668-669).

${ }^{8}$ Impensable sería pretender justificar el conjunto de esta perspectiva en un trabajo tan concreto como el presente. Baste una referencia accesible: Michelle Perrot alaba el nacimiento de una antropología económica, de la mano de Jacques Goody y Aleksandr Chayánov, y afirma contundentemente: "Con o sin patrimonio, la familia es un sistema económico", y más adelante: "En los ambientes rurales, el hogar es la unidad económica de base. La familia y la tierra se confunden, y sus necesidades se imponen a los individuos que las componen" (Perrot 1989: 114). 
En efecto, desde el siglo XIX las mujeres pudieron acceder a las fábricas, fundamentalmente textiles (y no sin superar antes ciertas trabas morales y legales); pero hay multitud de testimonios que prueban el trabajo asalariado de las mujeres casadas en épocas anteriores, cuya importancia no hay que minusvalorar. Así por ejemplo, en el siglo XVII había oficios desempeñados también por mujeres, quienes formaban parte de los respectivos gremios: aprensadoras, tintoreras, prestamistas, arrendatarias, lavanderas, verduleras, vendedoras, taberneras, bodegueras, costureras, criadas, mozas de servicio, etc. (Aguado et al. 1994: 265-270). En la Edad Media hispánica también existió el trabajo femenino asalariado: en el ciclo de labranza, de construcción, como sirvientas de casas, parteras, nodrizas y amas de cría; e incluso desde entonces hasta hoy ha habido mujeres propietarias y administradoras de tierras, especialmente en las regiones donde existe el sistema de heredero único en la sucesión de bienes (Aguado et al. 1994: 205-214) .

El trabajo no remunerado en la casa, sin embargo, seguía siendo el principal y el que más horas llevaba, llegando a configurar gran parte de la identidad femenina de todos los tiempos a través de lo que se ha dado en llamar "discurso de la domesticidad" de la mujer.

Tenían trabajos específicos propios en el seno del grupo familiar relacionados con la vida material como cocinar, lavar, coser, pero sobre todo conservar los alimentos, ordenar las raciones alimentarias, distribuir los bienes de todo tipo. [...] Cumplían, y era lo más importante, con el principal papel en la reproducción biológica, sobrellevaban el embarazo trabajando - muchas veces con igual intensidad que los otros-; la lactancia y los cuidados debidos al hijo solían interrumpir brevemente sus labores y quitarles horas de descanso (Pastor 1992: 569) ${ }^{10}$.

Pero además de estas obligaciones, asalariadas y del hogar, está lo que aquí más nos interesa por su relación con nuestro romance: la realización de faenas agrope-

\footnotetext{
9 También en otras regiones de Europa las familias requerían del dinero ingresado por las mujeres del grupo doméstico para su subsistencia o prosperidad: «El ámbito familiar, que reúne a sus miembros para comer y charlar, los dispersa para trabajar. [...] Así se comprueba cuando se analizan las estrechas relaciones establecidas entre el monasterio de Monte Oliveto (Siena) y las familias de sus aparceros (1400-1430). Las mujeres hilan el lino por cuenta de los monjes, tejen la lana, y lavan los paños, y, en este trabajo asalariado, se suceden casi todas las de la familia" (De la Roncière 1989: 215).

${ }^{10}$ Françoise Piponnier ofrece también una enumeración de las tareas de la mujer casada en las sociedades preindustriales de Europa: cuidar y alimentar a los niños, preparar el fuego, hacer el guiso, recoger el agua, elaborar el pan, limpiar la vajilla, mantener la limpieza del resto de la casa, encargarse de la ropa, etc., aparte, claro está, del trabajo textil con fines comerciales, práctica muy difundida en el medio rural (Pipponier 1992: 405-410). Olwen Hufton, desde una perspectiva que trata de ser europea (aunque atiende más a la Europa nórdica y anglosajona), habla de la mujer en las unidades rurales y su trabajo doméstico: "His wife was an organizer. She supervised the kitchen and the meals that were provided for the farm hands. She ruled the dairy and could in her own right be responisble for business negotiations concerned with the sale of products. She could give orders to men as well to the dairymaids and kitchen helper. [...] The farmer expected his wife to be a worker. Failure to have her full support services was seen as a just cause for marital grievance" (Hufton 1995: 152), y remite a los cuadros de Jan Siberecht La Cour de la ferme (1664) y La Ferme des Maraîchers (1664), en los que se representa el trabajo de las mujeres en las granjas.
} 
cuarias. La actividad económica de subsistencia de la familia no se basa sólo en las ganancias monetarias traídas desde el exterior: en el mundo rural, debido a los límites de sus comunicaciones, ha existido siempre una conciencia de autoabastecimiento de gran parte de los bienes consumibles, basada en la explotación de pequeños huertos, cuadras, corrales, etc., y en el sistema de trueque de algunos de sus productos derivados ${ }^{11}$. En muchas regiones de España la mujer colaboraba y colabora en tareas relacionadas con el ganado de la familia o con la labranza. Lo curioso es que es precisamente en áreas del norte de la Península donde esto es más frecuente, coincidiendo con las regiones donde se ha conservado La noble porquera ${ }^{12}$.

Para dar un panorama algo más completo de los trabajos de la mujer en el campo español, y en concreto de sus trabajos agropecuarios, refirámonos a continuación a dos de los estudios más minuciosos al respecto, uno sobre Zaragoza y otro sobre Cantabria. En ellos se distingue asimismo entre unas zonas y otras, por lo que no hay que entender las peculiaridades del trabajo de la mujer como un denominador común, ni siquiera en el ámbito provincial. Los diferentes tipos de economía de cada localidad condicionan las faenas que cada parte de la unidad familiar ha de realizar: en el Prepirineo y el Somontano, según Rivas (1986), las actividades se realizan, la mayoría de las veces, fuera de casa, mientras que en la región de los Monegros las mujeres realizan sus tareas en el recinto doméstico, normalmente dentro del patio:

La economía de subsistencia de estas zonas [Prepirineo y Somontano] precisa de todo el tiempo de la familia y la clase de actividades que desarrollan son, la mayoría de las veces, fuera de la casa: el hombre dedicado a las faenas agrícolas y la mujer a las faenas del ganado. [...] Actualmente, ella "hace la leña fina" para encender el fuego y la transporta al corral y del corral a la casa; tener siempre leña preparada es misión de la mujer, así como "muir" las cabras, ovejas y vacas por la mañana y por la tarde, sacar las cabras y ovejas a la vicera; llevar el ganado a pastar cerca del pueblo; ir a regar, cuidar de "la tajadera" por donde sale el agua; ir a la recolección de la patata, la remolacha, el maíz, la uva, las olivas, las almendras y no sólo trabaja para su casa, sino también para otros "a jornal" (Rivas 1986: 37-38).

La mujer de ribera y de secano, la mujer de los Monegros, del Valle del Ebro, del Jiloca, Jalón, por el contrario, hace un mayor uso del patio [...]. [Al ser agricultura extensiva y haber entrado la máquinal la mujer ha quedado libre de una serie de faenas propias de ella como hacer fajos de mies, recoger gavillas, llevar la comida a los hombres, ayudar a trillar, aventar, así tiene más tiempo libre para otra serie de labores como calceta, ganchillo, costura, trabajos todos que puede hacer sentada en el patio, cuando el tiempo lo permite, o atrás en el corral (Rivas 1986: 38).

\footnotetext{
${ }^{11}$ Ver Perrot (1989: 117-118), aunque nos podría bastar nuestra propia experiencia de los campos de España: "Lo más general es que el autoconsumo familiar, la producción del pequeño huerto — esos 'cuadros' de hortalizas encaramados incluso sobre las 'fortificaciones parisinas'-, los intercambios de servicios o de bienes de una economía ampliamente basada en mutuas contradonaciones constituyan otros tantos eficaces quites frente a la penuria y la miseria. Suponen unas relaciones horizontales cuya desaparición, en las sociedades contemporáneas, explica una mayor vulnerabilidad ante el paro, una mayor dependencia frente al Estado".

${ }^{12}$ A excepción de las comunidades sefardíes, que probablemente lo mantienen, como han mantenido muchísimas otras tradiciones de la época anterior a su expulsión, por su función de vínculo identitario: en vistas al fin de cohesionar comunidades pequeñas en países extranjeros y de otra religión, cuya lengua a veces ni hablan, y de evitar la disgregación (Cf. Menéndez Pidal 1968: II, 330-340; y Benmayor 1979: 12).
} 
En el primero de estos casos, en zonas de montaña, encontramos que el trabajo de la mujer no se distingue apenas del castigo que la suegra impone a la nuera en nuestro romance: el cuidado del ganado y la recogida de la leña es lo que le manda hacer en las versiones donde la tarea queda más especificada (las catalano-aragonesas, que son más cercanas en este punto al original francés de La porcheronne), e igualmente es lo que realiza la mujer del Moncayo y del Prepirineo aragonés.
Quan don Guillem va ser fora, porqueirola l'han fan ser.
-Porqueirola, porqueirola, és hora d'anar a avier:
els porquets fan nyigro-nyigro, y també fan nyigronyé.
Lleva't la roba de seda i posa't la de borrer,
pren el fus i la filosa, set fusades n'has de fer,
$i$ encara que pleguis vospre un feix de llenya també ${ }^{13}$.

No así en otras comarcas más llanas, donde el tipo de agricultura ha permitido que hoy esas labores difieran (aunque quizá no antes de la entrada de la máquina). En Cantabria también existen situaciones diversas:

[En Trasmiera:] Así pues, sólo mediante una familia extensa con suficientes miembros como para hacer frente a todo el trabajo, se puede mantener una economía mixta del tipo aquí descrito [trabajo en fábrica y explotación agraria familiar]. [...] Ya hemos visto cómo el hombre se dedica más bien al trabajo fuera de la explotación, es decir, en la fábrica o los servicios, y la mujer es la que se queda más tiempo al cuidado de las faenas agrarias; si bien se pueden dar casos de mujeres realizando tareas asalariadas, esto es menos frecuente (Rivas 1991: 32).

[En Liébana:] Si bien la mujer lebaniega realiza las mismas labores que el hombre, al permanecer éste más tiempo en la explotación familiar, la mujer queda relegada a un segundo lugar. [...] Cuando el hijo mayor se casa y lleva a la nueva esposa a su casa paterna, es la madre la que, junto con el marido y el hijo, atenderá el ganado y las faenas del campo, mientras que la mujer joven se quedará en casa al cuidado de los niños, la comida, la limpieza, y los animales domésticos (Rivas 1991: 39-40).

Según vemos, la mujer trabaja en faenas agropecuarias cuando es necesario, y esto suele equivaler a casi siempre en las economías tradicionales de subsistencia, basadas en pequeñas propiedades de tierra. Este último texto citado presenta además un interés adicional al aclarar ciertas diferencias entre el trabajo de la suegra y el trabajo de la nuera. Volviendo a nuestro romance, las causas por las que se considera que la esposa de La noble porquera no debería trabajar cuidando el ganado o recogiendo leña serían, con todo lo que hemos dicho: o bien que pertenece a una clase suficientemente acomodada, o bien que pertenece a una región geográfica (dentro del mundo de la ficción, claro está) en que la mujer no trabajase normalmente en el campo. Enseguida pasaré a valorarlas.

\section{COTEJANDO EL ROMANCE CON LA REALIDAD}

El motivo del trabajo de la nuera como castigo por su suegra resulta significativo a la hora de entender las causas que mueven a los transmisores del romance a per-

\footnotetext{
${ }^{13}$ Versos 19-24 de una versión de Barcelona, de Teresa Gelats, recogida por Joan Amades antes de 1951 (Amades 1951: II, 721-723).
} 
petuar determinadas fábulas y no otras, dentro de sus expectativas y entorno cultural. Me propongo hablar, en otras palabras, de las conexiones entre el mundo contenido en las narraciones orales y aquél en el que viven las personas que las cantan.

He mencionado antes que la coherencia de la intriga se sostiene debido quizás a la posición aristocrática de los protagonistas, pues pretender (como pretende el marido) que una mujer no colabore en las tareas económicas de una casa, sino que se pase los días mano sobre mano, no es creíble a nivel narrativo a menos que nos estemos refiriendo a clases nobles o muy pudientes. Esto implicaría una consecuencia directa y clara acerca del modo de transmisión del romancero: que los informantes lo conservan en su memoria oral sabiendo que están comunicando cosas que pertenecen a otro mundo (el ficcional, que habla de reyes y nobles), del que entienden los códigos, pero que no se corresponde en algunos aspectos con el suyo propio. No nos sorprende: es, al fin y al cabo, lo habitual cuando hablamos de transmisión de literatura de ficción, desde los cuentos maravillosos hasta la novela actual.

Pero existe la posibilidad, como la crítica romancística suele sostener, de que el romance hable, en algún sentido, de las circunstancias propias del mundo de los informantes, o análogas a ellas. "Las narraciones tradicionales, salvo los casos en que su canto se ha ritualizado, conservan su primaria función cultural de ser 'ejemplos' de vida" (Catalán 1997: 243), se dice. ¿Qué ocurriría si esto fuera así? Sencillamente, se plantearían algunas contradicciones que habría que intentar explicar, al menos en el caso de La noble porquera. Me explico: supongamos que el motivo por el que se pide que esta mujer no trabaje estuviera relacionado con una geografía hipotética en que las mujeres no fueran necesarias para la economía doméstica, y que dicha geografía se identificase en consecuencia con la de los propios informantes (puesto que los romances no son para quienes los conservan ensayos histórico-geográficos ni tratados etnológicos). Siendo así, se presenta un hecho llamativo: las versiones conservadas de La noble porquera pertenecen todas a regiones minifundistas, que como se ha expuesto exigen mayor trabajo de la mujer ${ }^{14}$. ¿Cómo afirmar entonces que nuestro romance toma partido por la nuera, quien ve el trabajo en el campo como un castigo? Y sin embargo no hay duda de que lo hace, y que en el conflicto entre suegra y nuera ésta última es la víctima. La cuestión se complica si añadimos que existen testimonios que señalan que La noble porquera era cantado justamente por mujeres mientras cuidaban el ganado en los pastos. Maria Serra i Vilalta, una informante de Ogassa ${ }^{15}$, aprendió el romance "del seu pare, dels segadors, pastors, etc. mentre guardava bestiar" (Pujol et al. 1928: 292). Y Joan Amades declara que "aquesta cançó havia estat típica de les porqueroles i guardadores de porcs, que la cantaven tot guardant i filant i que es venien a sentir com identificades amb la protagonista" (Amades 1951: II, 723). ¡De modo que el trabajo de la esposa del romance, criticado en él como una abomina-

\footnotetext{
${ }^{14}$ Más que una distinción geográfica norte-sur en cuanto a la necesidad del trabajo femenino, debemos pensar en una distinción entre localidades con una explotación minifundista y localidades con una explotación latifundista de la tierra. En las primeras el trabajo agropecuario de la mujer es vital, mientras que en las segundas, debido a la mayor exigencia física de las explotaciones y, recientemente, a la introducción de la maquinaria, no es tan imprescindible.

${ }^{15}$ En la provincia de Gerona; recitó en 1923 una versión de La noble porquera que recogieron Joan Tomàs y Bartomeu Llongueres, y que fue publicada en Tomàs (1928: 290-292).
} 
ción, es precisamente la causa de que el romance se cante en estas regiones, en que las mujeres realizan las mismas faenas como parte aceptada de su contribución a la prosperidad doméstica!

Sin duda hemos de echar por tierra muchos de los prejuicios con que acudimos a la lectura de un romance. A la luz de estos datos, nada sería más errado que afirmar que La noble porquera expresa conscientemente una defensa contra los "abusos" ejercidos sobre la mujer de las sociedades tradicionales. Todo lo contrario: parece que se cuenta de forma análoga a como una niña de una familia igualitaria de hoy pueda arrancarse un día a contar el cuento de La bella durmiente, es decir, sin implicaciones conscientes de un mundo en el otro, en cuanto al ámbito material se refiere. En ningún caso intenta este romance crear un estado de opinión para propiciar que las mujeres de futuras generaciones se liberen de una carga de trabajo que el campo les impone, más bien lo contrario: esas mismas mujeres han estado cantándolo durante siglos sin ningún éxito aparente en ese sentido. La inexistencia de este romance en las regiones del sur y centro de la Península se debe a que no se da una situación similar en la vida real por la que las transmisoras se puedan "sentir com identificades". Parece como si a las mujeres del norte les gustara conservar La noble porquera sólo porque habla de un personaje que hace oficios parecidos a los suyos, sin reparar en que detrás de ello hay un mensaje obvio de liberación de esas cargas. Así pues, sorprendentemente, este romance mantiene el status quo gracias a que "gusta" a las informantes el encontrar un personaje que se dedica a lo que ellas se dedican. Esta constatación no puede sino recordarnos las conclusiones de Marvin Harris acerca de las interrelaciones de la superestructura y la infraestructura (utilizando los términos de su análisis cultural): la literatura se convierte de un modo u otro en responsable de una retroalimentación negativa que mantiene los pilares materiales del sistema (Cf. Harris 2001: 70-75).

En definitiva, habrá que matizar en adelante en qué y cómo se concretan los "Contenidos ideológicos útiles" que, a pesar de las desactualizaciones de su nivel discursivo, transmite supuestamente el romancero. Una interesante línea de los estudios romancísticos en las últimas décadas es la antropológica y materialista (Catarella 1994; Lorenzo Vélez 1986 y 1989; Anahory-Librowicz 1995). Este punto de vista estableció cómo la literatura oral podía servir de mecanismo de subversión ideológica y de factor motor de cambio sociológico. Sin duda podrá seguir ofreciendo muchos frutos y perspectivas valiosísimas en los próximos años, pero siempre si se atiende a que los contenidos admonitivos que le aporta un romance a su transmisor son difíciles de generalizar: no todo lo que se muestra en el romance es como parece. Nos preguntamos: ¿por qué se canta y conserva La noble porquera? Y caemos en la cuenta de que no hay una relación unívoca entre "situación criticada" (el trabajo de porquera o pastora) y "mensaje crítico" (supuestamente contrario a esos trabajos).

Con certeza la clave de todo está en que, a fin de cuentas, no lo olvidemos, el romancero plantea mundos ficticios. Es plausible que en esto los diferentes géneros narrativos de tradición oral compartan semejantes mecanismos de significación e interpretación, de modo que no parece ingenuo comparar la escucha de romances tradicionales con la de cuentos "de hadas". Por un lado, la interpretación del trabajo (femenino) como un castigo aparece en consonancia con la ideología común en los relatos orales ofrecidos a las generaciones jóvenes durante sus procesos de socializa- 
ción: el trabajo no es deseable y es cosa de pobres, en la sociedad aristocrática y clasista de estos relatos ficcionales (Cf. Cerda 1985: 395-405, con los matices que añade Lurie 1998: 32-43). Por otro, "el cuento es terapéutico porque el paciente $[i$. e. el informante o el oyente] encuentra sus propias soluciones mediante la contemplación de lo que la historia parece aludir sobre él mismo y sobre sus conflictos internos, en aquel momento de su vida" (Bettelheim 1999: 31). Y en cuanto a la identificación con los protagonistas, como acabamos de ver en las cantoras catalanas, puede ocurrir lo mismo que con los cuentos de la infancia, en los que se obvia en un principio la dimensión moral: "las elecciones de un niño se basan más en quién provoca sus simpatías o su antipatía que en lo que está bien o está mal» (Bettelheim 1999: 15).

En definitiva, hay que tener el cuidado de no interpretar el trabajo impuesto a la nuera en el sentido en que lo interpretaríamos con nuestros ojos urbanos y contemporáneos. ¿Cómo lo veían las mujeres que cantaban el romance y al mismo tiempo cuidaban a los cerdos o recogían gavillas? No es que haya que asumir como "felices" para los cantores del romance los hechos desgraciados que le ocurren a la nuera, pero sí hay que ver ese "castigo" desde su óptica. Seguramente esos informantes no le darían tanta importancia al trabajo en el campo como parte del castigo humillante de la suegra, pues ellos lo realizaban también, y no como condena sino como deber. Es muy posible que la peor parte del trato que recibe la nuera fuera para ellos más bien la expulsión del techo, el alejamiento durante el día y el maltrato durante la noche, es decir, la degradación de esposa a criada-pastora, el racionamiento de la comida, el ayuntamiento con los perros y gatos, y sobre todo el trato desigual respecto a las hijas "de la casa". La negación, en definitiva, de su estatus, la muerte social dentro del grupo doméstico, frente a la que el marido, mientras está ausente, no puede hacer nada, y su propia familia de sangre, al hallarse lejos, tampoco.

\section{BIBLIOGRAFÍA CITADA}

Aguado, A. M. et al. (comps.). 1994. Textos para la historia de las mujeres en España. Madrid: Cátedra. Amades, J. 1951. Folklore de Catalunya, 4 vols (vol. 2: Cançoner). Barcelona: Editorial Selecta.

Anahory-Librowicz, O. 1995. "La función de la transgresión femenina en la estructura narrativa del romance", en Caspi, M. (ed.), Oral Tradition and Hispanic Literature. Studies in Honor of Samuel G. Armistead: 385-399. Nueva York: Garland.

Benmayor, R. 1979. "Social Determinants in Poetic Transmission or A Wide-Angle Lens for Romancero Scholarship", en Armistead, S., Sánchez Romeralo, A. y Catalán, D. (eds.), El romancero boy: bistoria, comparatismo, bibliografía crítica: 153-165. Madrid: Cátedra-Seminario Menéndez PidalUniversity of California.

Bettelheim, H. 1999. Psicoanálisis de los cuentos de hadas. Barcelona: Crítica.

Bonte, P. e Izard, M. 1996. Diccionario Akal de Etnología y Antropología. Madrid: Akal.

Catalán, D. 1997. Arte poética del romancero oral. Parte 1a․ Los textos abiertos de creación colectiva. Madrid: Siglo XXI.

Catarella, T. 1994. "Hacia una sociología del romancero", en Catalán, D., Cid, A., et al. (eds.), De balada y lírica: I, 409-425. Madrid: Fundación Menéndez Pidal- Universidad Complutense.

Ceballos Viro, I. 2010. "El romancero tradicional y las relaciones de parentesco: la suegra malvada" (tesis inédita). Madrid: Universidad Complutense <http://eprints.ucm.es/10606/1/T31862.pdf >.

Cerda, H. 1985. Ideología y cuentos de hadas. Madrid: Akal.

De la Roncière, Ch. 1989. "La vida privada de los notables toscanos en el umbral del Renacimiento", en Ariès, Ph. y Duby, G. (dirs.), Historia de la vida privada: II, 163-309. Madrid: Taurus. 
Harris, M. 2001. Cultural Materialism: The struggle for a science of culture. Walnut Creek (California): Altamira Press.

Hufton, O. 1995. The Prospect Before Her. A History of Women in Western Europe. Londres: Fontana Press.

Lévi-Strauss, C. 1995 [1956]. "La familia", en Shapiro, H. (ed.), Man, Culture and Society. Londres: Oxford University Press. Citado por la edición de Velasco, H. (comp.), Lecturas de antropología social y cultural: 295-318. Madrid: UNED.

Linton, R. 1993 [1936]. The Study of Man: An Introduction (Estudio del Hombre). Citado por la edición de Martín López, E. (comp.), Textos de sociología de la familia. Madrid: Rialp.

Lisón Tolosana, C. 1974. "Estrategias matrimoniales, individuación y 'ethos' lucense", en Lisón, C., Perfiles simbólico-morales de la cultura gallega: 61-97. Madrid: Akal.

Lisón Tolosana, C. 1980. Invitación a la antropología cultural de España. Madrid: Akal.

Lorenzo Vélez, A. 1986. "Literatura de tradición oral y antropología”. Revista de Folklore 66 (6): 193198.

Lorenzo Vélez, A. 1989. "Ideología y visión del mundo en el romancero tradicional", en Piñero, P., et al. (eds.), El Romancero. Tradición y pervivencia a fines del siglo XX: 93-100. Cádiz: Fundación Machado-Universidad de Cádiz.

Lurie, A. 1998. No se lo cuentes a los mayores. Literatura infantil, espacio subversivo. Madrid: Fundación Germán Sánchez Ruipérez.

Massot i Muntaner, J. et al. 1996-2007. Memòries de Missions de recerca, vols. IV-XVII. Barcelona: Abadia de Montserrat.

Menéndez Pidal, R. 1968. Romancero hispánico (Hispano-portugués, americano y sefardí). Teoría e bistoria, 2 vols. Madrid: Espasa-Calpe.

Milà i Fontanals, M. 1882. Romancerillo catalán. Canciones tradicionales. Barcelona: Álvar Verdaguer.

Murdock, G. P. 1965. Social Structure. Nueva York-Londres: The Free Press-Collier-Macmillan Ltd. (1르 ed. 1949).

Nash, M. 1993. "Identidad cultural de género, discurso de la domesticidad y la definición del trabajo de las mujeres en la España del siglo XIX", en Duby, G. y Perrot, M. (eds.), Historia de las mujeres en Occidente, vol. IV: El siglo XIX: 585-597. Madrid: Taurus.

Pastor, R. 1992. "El trabajo rural de las mujeres en el reino de Castilla, siglos XI-XV", en Duby, G. y Perrot, M. (dirs.), y Klapish-Zuber, Ch. (coord.), Historia de las mujeres en Occidente, vol. II: La Edad Media: 565-579. Madrid: Taurus.

Perrot, M. 1989. "Figuras y funciones", en Ariès, Ph. y Duby, G. (eds.), Historia de la vida privada, vol. IV: De la Revolución Francesa a la Primera Guerra Guerra Mundial: 127-191. Madrid: Taurus.

Petersen, S. et al. (eds.). 1980. A.I.E.R. (Archivo Internacional Electrónico del Romancero): Voces nuevas del romancero castellano-leonés, vol. I. Madrid: Cátedra-Seminario Menéndez Pidal.

Piponnier, F. 1992. "El universo de la mujer: espacios y objetos", en Duby, G. y Perrot, M. (dirs.), y Klapish-Zuber, Ch. (coords.), Historia de las mujeres en Occidente vol. II: La Edad Media: 401417. Madrid: Taurus.

Pujol, F. et al. 1928. Memòries de missions de recerca, estudis monogràfics, cròniques (Materials de l'Obra del Cançoner Popular de Catalunya), vol. 1, fasc. 2. Barcelona: Abadia de Montserrat.

Rivas, A. M. 1986. "La familia como unidad doméstica de producción y de parentesco, generadora de identidad", en Ritos, símbolos y valores en el análisis de la identidad en la provincia de Zaragoza: 15-171. Zaragoza: Caja de Ahorros de la Inmaculada.

Rivas, A. M. 1991. Antropología social de Cantabria. [Cantabria]: Universidad de Cantabria.

Segalen, M. 1992. Antropología bistórica de la familia. Madrid: Taurus.

Stein, H. 1979. Zur Herkunft und Altersbestimmung einer Novellenballade: Die Schwiegermutter beseitigt die ihr anvertraute Schwiegertochter (DVldr Nr. 76 und Nr. 77). Helsinki: Suomalainen Tiedeakatemia.

Tomàs, J. et al. 1928. Memòries de missions de recerca, estudis monogràfics, crònica (Materials de l'Obra del Cançoner Popular de Catalunya), vol. 2. Barcelona: Abadia de Montserrat. 


\section{APÉNDICE DE TEXTOS:}

Versión de Uznayo (Polaciones, Cantabria), de Mariuca, de 80 años. Recogida por Diego Catalán y Álvaro Galmés en agosto de 1948. Publicada en Ceballos (2010: 535-537).

[Contaminada con El ciego raptor en sus 37 primeros versos.]

38 Apenas allegó don Narbueso a la mesa

cuando le vienen cartas que tenía que ir a la guerra.

40 -Madre, la mi madre, si bien me queréis

a la mi esposita me la regalaréis,

42 por la mano a misa me la llevaréis.

-Vaste, hijo mío, tú vaste a la guerra,

44 que la tu esposita bordará la seda.-

Púsolas un día de dos en dos:

46 lo de Marianita estaba lo mejor.

Púsolas un día de tres en tres:

48 lo de Marianita estaba más bien.

Púsolas un día de cuatro en cuatro:

50 lo de Marianita estaba más guapo.

-No lo vales, no, para bordar la seda,

52 váleslo mejor para guardar ovejas.-

Apenas allegó don Narbueso a la guerra

54 cuando Marianita lloraba allá en la sierra:

"Mi marido se fue, mi marido vendrá,

56 que si no viene luego ya no tardará;

Dios me lo llevó, Dios me lo volverá".

58 -Váyanse, señores, por esos caminos, que voy a ver quién llora arriba en estos riscos.

60 Váyanse, señores, por ese atajo, que voy a ver quién llora arriba en estos altos.

62 Diga usted, zagaleja del lindo mirar, una oveja de éstas ya me la dará.

64 -Eso no, señor, no, señor melitar, mi suegra es muy mala y me los podrá contar.

66 -Diga usted, zagaleja del dulce mirar, un carnero de ésos ya me le dará.

68 -Eso no, señor, no, señor melitar, mi suegra es muy mala y me los podrá contar.

70 -Diga usted, zagaleja del dulce mirar, de la su merienda un poco me dará.

72 -Eso no, señor, no, señor melitar, mi suegra es muy mala y poco me echó,

74 por discurso del día tomémelo yo.

-Diga usted, zagaleja del dulce mirar

76 si encontraré esta noche donde me alojar. —Eso sí, señor, sí, señor melitar,

78 en casa de mi suegra alojamiento habrá; por una casa buena puede usted preguntar.

80 - Ponte, Marianita, los vestidos de seda, que tenemos en casa gente de la guerra.

82 Ponte, Marianita, los vestidos de grana, que tenemos en casa gente de La Habana. 
84 -No los pongo, no, los vestidos de seda, que me pegarán los pelitos ' las ovejas.

86 No los pongo, no, los vestidos de grana, que me pegarán pelitos ' las cabras.

88 ¿Quién colgó aquí espada y capote donde cuelgo yo mi zurrón a la noche?

90 ¿Quién colgó aquí capote y espada donde cuelgo yo mi zurrón y cayada?

92 - Ya viene la pastora metiendo ruido. -Eso será porque trae frío.

94 -Quítate, mi perro, quítate, mi gato, que esa es la cama donde yo descanso.

96 Quítate, mi gato, quítate, mi perro, que esa es la cama donde yo me acuesto.

98 -Dime, zagaleja del dulce mirar, ¿no tienes otra cama donde descansar?

100 -Eso no, señor, no, señor caballero, que hace ya siete años que duermo en este suelo.

102 -Diga usted, la patrona del lindo mirar, ¿tiene usté una gallina para yo cenar?

104 Y la pechuguita pa' la pastorcita será. -Eso no, señor, no, señor caballero,

106 están aquí mis hijas que lo son primero; a la pastorcita ya habrá viera y suero.

108 -Diga usted, la patrona del lindo mirar, ¿tiene usted una cama para yo descansar?

110 Y una hija de usted me irá a alumbrar. —Eso no, señor, no, señor melitar,

112 si acaso la pastora le irá a alumbrar. (Y ella que lo oyó por la ventana más alta se quiso [tirar]) Calla, pastorcita del lindo mirar

114 coge tu candil y venme a alumbrar de la puerta al cuarto tú te volverás.

116 - Si tú eres don Narbueso yo soy doña Mariana. - Sortijitas de oro a ver cómo apretaban.

118 Arriba, la pastora del dulce dormir, que la oveja bala y quiere salir.

Notas: añade tras 45: "con dos hijas que tenía", y tras 54: "cantaba". 23b: granina es grana: paño fino usado para trajes de fiesta (DRAE).

Versión de Sant Joan Despí (Sant Joan Despí, Barcelona), de Filomena Gil, de 90 años. Recogida por Joan Tomàs y Joan Amades, en el verano de 1931.

Publicada en Massot i Muntaner (ed.) et al. (1996-2007: XIV, 384-385); reeditada en Ceballos (2010: 549-550).

- Per què no es casa, don Jaume? Per què no es busca muller?

2 Casi's amb donya Dolores, que és filla d'un cavaller.El dilluns en fan els tractes i el dilluns ja se'n casé,

4 i el dimarts en reben carta que a la guerra en té d'aner. -Jo us encomano, ma mare, us encomano ma muller,

6 que no li feu fer cap feina que ella no la'n pugui fer. 
No li feu passar bugada ni posar la mà a paster.

Compreu-li una cadireta i assenteu-la en el carrer,

i ensenyeu-la'n de fer mitja;

10 si la mitja no li agrada, enseyeu-la'n de broder;

si el broder no li agrada, ensenyeu-li'n del planxer;

12 si el planxer no li agrada, enseyeu-li'n de punter.-

Quan don Jaume va ser fora, porquerola la'n fan ser.

14 Li treu el vestit de seda i li posa el borrasser;

li treu les arracadetes i a sa filla els posé.

16 -Vamos, vamos, porqueirola, que és hora d'anar a avier.

- Bé em dirà, la mia sogra, què em darà per a menger.

18 -Un bocinet de pa d'ordi, d'arestes no es pot menger.

- Ja em dirà, la mia sogra, què me’n dóna per bebé.

20 - Un porronet de vi agre, que la terra fa estarrufer.

-Bé em dirà, la mia sogra, qué me'n dóna per tasquer.

22 - Te'n dono set serradetes i un feix de llenya també.

- Bé em dirà, la mia sogra, a on aniré a avier?

24 -Vés pels camps i les vinyetes, que a sobre hi ha bon herber.

-Camineu, camineu, patxos, jo també caminaré.

26 En sento una veu hermosa, me pareix que és ma muller.

Déu la guard, la porqueirola. -Déu lo guard, lo cavaller.

28 - Bé em dirà la porqueirola a on ne solen llotger.

-Vagi a casa de don Jaume, que allí en solem llotger.

30 Ai de mi, la pobra sogra, quina tasca tinc de fer.-

Ell s'arrenca de l'espasa, ja n'hi feia un 'vellaner.

32 Amb el sorroll de les branques ja n'hi fuig el gros mesquer.

- Ai, pobra de mi, la sogra, que con jo arribaré.-

34 -No s'espanti, porqueirola, que jo ja la'n guardaré.

Déu la guard, la missenyora. -Déu lo guard, lo cavaller.

36 -Bé em dirà la missenyora si en tindrien allotger.

—Que hi vingui la porqueirola, la filla la'n guardaré.-

38 - Set anys que no he dormit amb home i altres set que hi dormiré.

N'he dormit a la cendrera, com si fos un gat mesquer.-

40 L'endemà a la matinada sa sogra ja la'n cridé.

-Vamos, vamos, porqueirola, que ja és hora d'anar a avier.

42 -Que hi vagi la vostra filla, ma muller la'n guardaré.

Si no em fóssiu mare pròpia, jo us en mataria bé.

Estribillo: I adiós, Dolores, / ai de la noble ciuté.

Versión de Villaneuve des Escaldes (Llívia, Gerona), de Teresa Solé, de 70 años.

Recogida por Joan Tomàs y Joan Llongueres, en el verano de 1935.

Publicada en Massot i Muntaner (ed.) et al. (1996-2007: XVII, 299-300); reeditada en Ceballos (2010: 545-546).

Ara sí que arriba l'hora que don Jaume ha de partir,

2 que en té la muller xiqueta, i no la'n gosa deixar.

L'encomana a sa mare, sa mare l'encomané.

4 Li diu que no la faci anar a l'aigua, que el poal no pot porter.

-Compreu-li una filoseta, enseyeu-li de fuser.

6 Si el fuser no li agrada, ensenyu-li de broder.- 
Tan bon punt don Jaume és forma, porqueirola la'n fan ser.

$8-\mathrm{Ai}$, mira, tu, porqueirola, set fusades tens de fer al cap de las set fusades, un feiz de llenya també.-

$10 \mathrm{Al}$ cap de la setena, son marit ja és arribé.

-Baixos, baixos, caballeros, i los patxos a troter,

12 que aquesta veu que jo sento, jo mi apar que és ma muller.

—Déu la gord, la porqueirola. - Benvingut, el cavaller.

14 -No em diríeu, porqueirola, l'hostal nou a veure on é?

—L'hostal nou és a casa ma sogra, i allà on solia ser.

16 -No em diríeu, porqueirola, la berena a veure on é?

-Un bocí de cosa d'ordi no agradaria a vosté?

18 -No em diríeu, porqueirola, si és hora d'anar a embasser?

-No és hora d'embasser encara, set fusades tinc de fer,

20 i al cap de les set fusades, un feix de llenya també.-

I amb la punta de l'espasa el feix de llenya li fé.

22 Tenint aquestes paraules, si li escapa un llodriguer.

- Ai, pobra de mi l'esquena, anit jo bé em moriré.

24 -No tinguis por, porqueirola, no pas tant com jo hi seré.

-Déu lo gord, la jove hostessa, què hi hauria per soper?

26 -N'hi haurà perdius i gotlles i capons entre llarder.-

El primer bocí que talla per la porqueirola é.

28 -No em diríeu vós, hostessa, porqueirola a veure on é?

-Porqueirola és a l'escala i a modo d'un gos llebrer.

30 Puja, puja, porqueirola, i a soper amb el cavaller.

-Que hi vagin les vostres filles, que jo no hi tinc gaire acostumé.

32 -No em diríeu vós, hostessa, porqueirola amb qui airà cotxer?

-Que hi vagi amb el caballero, ja que ha sopat amb vostè.

34 - Set anys que el marit és fora, a mi cap home m’ha toqué.Si la'n prenen i la'n 'gafa i a la cambra la'n porté,

36 i a l'entrade de la cambra porqueirola s'esllomé.

- Porteu aiguardent, mestressa, que jo ja us el pagaré.

38 Porteu aiguardent, mestressa, que jo lajn retornaré.

—Amb alguna bastonadeta, jo bé la retornaré.

40 - Xeca't, 'xeca't, Francisqueta. 'Xeca't, 'xeca't, ma muller.

-Si vós el meu marit éreu, i una marca vos tinré.

42 Ensenyeu.me'n la cuixa dreta, que jo vos coneixeré.L'endemà matí avant dia l'hostessa ja la'n cridé:

44 - 'Xeca't, 'xeca't, Francisqueta, que és hora d'anar a engeguer. —Que hi vagin les vostres filles, que jo ja la gordaré.

46 Sinó que em sou mare mia, jo vos faria cremer, i de la cenra que faria jo la faria venter.

Estribillo: La dondeta / que la dondé.

Fecha de recepción: 29 de marzo de 2011

Fecha de aceptación: 21 de marzo de 2012 